\title{
Isolated extragenital HPV-thirties-group-positive bowenoid papulosis in an AIDS patient
}

\author{
D.J.FADER, M.H.STOLER* AND T.F.ANDERSON \\ Department of Dermatology, University of Michigan, 1910-0314 Taubman Center, Ann Arbor, MI 48109, U.S.A. \\ *Department of Pathology, University of Virginia Health Sciences Center, Charlottesville, VA, U.S.A. \\ Accepted for publication 15 December 1993
}

Summary We report a case of extragenital bowenoid papulosis in a man with AIDS. The lesions occurred on the anterolateral aspects of the neck, and were not associated with clinical genital or periungual involvement. In situ hybridization demonstrated abundant HPV DNA within the thirties group $(31 / 33 / 35)$, in the absence of HPV-16 or -18 .

The term 'bowenoid papulosis' (BP) was introduced in 1978 to describe multiple verrucous papules on the genitalia with a histological resemblance to Bowen's disease and a clinical resemblance to condylomata. ${ }^{1,2}$ $\mathrm{BP}$ is primarily a disease of sexually active young people, with a mean age of onset of about 30 years. $^{3}$ Multiple $2-10 \mathrm{~mm}$ red-brown or violaceous papules, some with a verrucous surface, may coalesce into plaques. The clinical spectrum includes lichenoid papules, erythematous macules and 'leukoplakia-like' lesions. ${ }^{3,4} \mathrm{BP}$ occurs most frequently on the genitalia, perianal skin or crural regions, and there is a slight female predilection. ${ }^{2-4}$ There are rare reports of extragenital BP with concomitant genital involvement. ${ }^{4-6}$ Histologically, BP exhibits many features of Bowen's disease: crowded, pleomorphic 'windblown' keratinocyte nuclei with occasional mitotic figures, and cytological atypia, which is usually less pronounced than in Bowen's disease. ${ }^{1-4}$ Viral features are characteristically absent on routine haematoxylin and eosin-stained sections, although BP is caused by a human papillomavirus. In essence, cutaneous and genital BP are HPV-induced mild, moderate, or severe degrees of intraepithelial dysplasia. We describe an AIDS patient with isolated extragenital bowenoid papulosis. In situ hybridization studies revealed an unusual HPV subtype.

\section{Case report}

A 48-year-old homosexual man was referred with a 2year history of asymptomatic, coalescing, warty papules

Presented in part at the American Academy of Dermatology meeting 4 December 1993, Washington, DC, U.S.A. on the neck. They initially developed unilaterally, but gradually encompassed both sides of the neck over a period of 12 months. He has been $\mathrm{HIV}^{+}$since 1985, and developed full-blown AIDS in 1989. His current CD4 lymphocyte count is $<100$ cells $/ \mathrm{mm}^{3}$. AIDS-defining illnesses have included recurrent Pneumocystis carinii pneumonia, pneumococcal pneumonia, and disseminated Mycobacterium avium-intracellulare infection. He gave a history of 'genital warts' many years ago, and these subsequently resolved. He could not recall the morphology of the lesions.

Physical examination revealed multiple, coalescing, red-brown, flat-topped verrucous papules, $5-10 \mathrm{~mm}$ in size, on the anterolateral aspects of the neck (Fig. 1). Examination of the genital and perianal regions did not reveal any abnormality. He was cachectic, and had extensive seborrhoeic dermatitis of the scalp and face, and diffusely xerotic skin. Most of his fingernails exhibited yellow discoloration distally, but were otherwise normal. Histology of a biopsy of a papule within a verrucous plaque on the neck showed bowenoid changes consistent with BP (Fig. 2). There were no viral features.

In situ hybridization for human papillomavirus (HPV) DNA types $6 / 11,16 / 18$, and $31 / 33 / 35$ was performed with three groups of probes, as directed by the manufacturer of the Viratype in situ hybridization kit (Digene Diagnostic, Gaithersburg, MD, U.S.A.), with minor modifications. In the prehybridization steps, the sections were pretreated with hydrochloric acid and proteinase $\mathrm{K}$, followed by denaturation in $95 \%$ formamide at $65^{\circ} \mathrm{C}$, as previously described. ${ }^{7}$ The remainder of the procedure was as recommended by the manufacturer, with the exception that the hybridization was carried out 


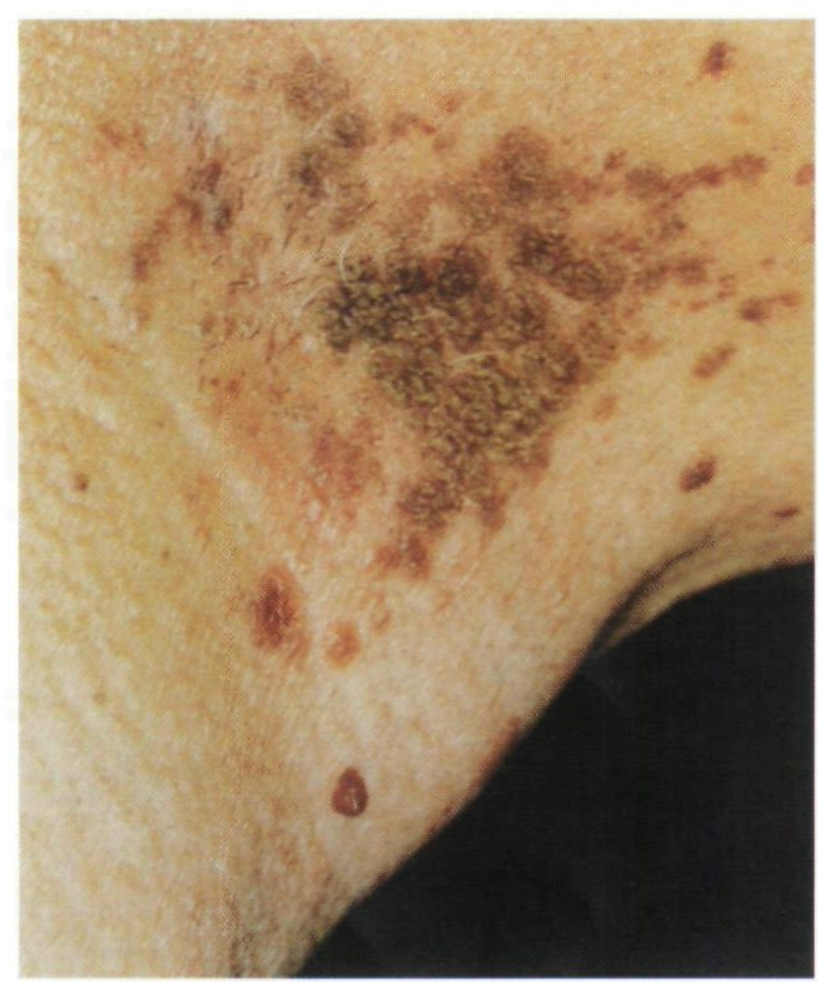

Figure 1. Multiple flat-topped, red-brown, verrucous papules are seen coalescing on the anterolateral aspect of the neck.

overnight, and the slides were developed in the chromagenic substrate for $2 \mathrm{~h}$ rather than $1 \mathrm{~h}$.

The results of in situ hybridization demonstrated high levels of HPV DNA of a type within the thirties group $(31,33$, or 35$)$. We did not have the probes to make an exact distinction. HPV-16 or -18 DNA was not detected (Figs 3a and b). The Omni probe assay was confirmatory. Positive and negative controls were also appropriate.

Clinical improvement has been achieved with periodic cryotherapy.

\section{Discussion}

BP can clinically resemble condylomata acuminata, and a prior history of genital warts is elicited in approximately one-third of BP patients. ${ }^{7,8}$ Immunostaining and molecular hybridization studies in the past decade have established human papillomavirus (HPV) as the causative agent of BP. ${ }^{4-6,8-10} \mathrm{HPV}-16$ is the viral agent most often involved, although a myriad of other types have been identified, including HPV-18, $31,32,34,35,39,42,48$, and $51-54 \cdot^{4-6,8-13}$ The association between HPV types 16, 18, 31-33, 35, 39 and carcinomas of the cervix and anus has raised the

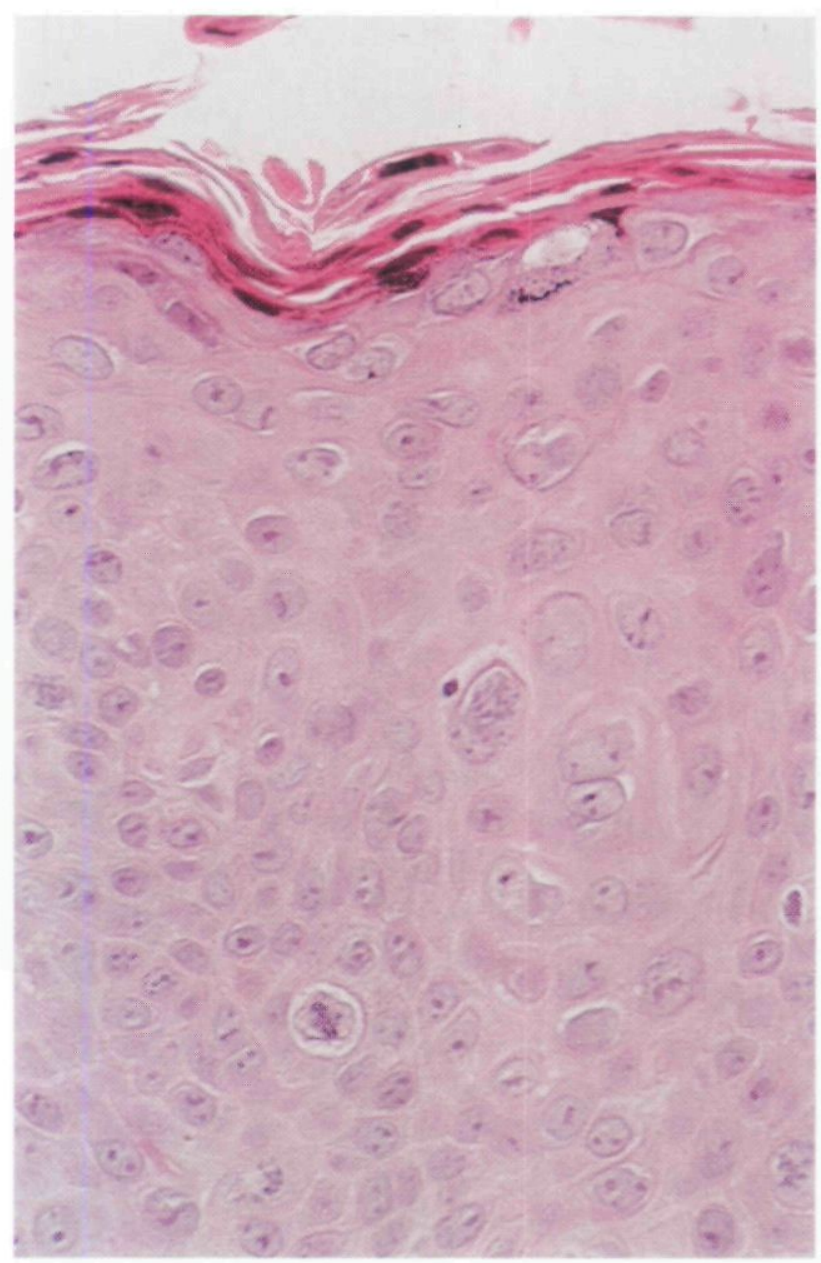

Figure 2. Photomicrograph of a papule from the neck, showing moderate bowenoid dysplasia with keratinocyte disorganization, nuclear anaplasia, and increased mitotic figures. This is less pronounced than in Bowen's disease (haematoxylin and eosin, $\times 100$ ).

possibility that BP may be a risk factor for the development of anogenital squamous neoplasias, particularly in the immunocompromised $\mathrm{HIV}^{+}$patient. ${ }^{5,10,14-16}$

Lookingbill et al. demonstrated HPV- $16^{+}$papules on the buccal mucosa in a patient with squamous cell carcinoma of the tongue and genital $\mathrm{BP}^{6}{ }^{6}$ and Rudlinger et al. reported a woman with $\mathrm{HPV}-35^{+}$ anogenital BP and concurrent HPV $-35^{+}$bowenoid dysplasia of a periungual lesion. ${ }^{13}$ Rarely, isolated extragenital HPV $-16^{+}$neoplasms have been reported on the extremities and in the aerodigestive tract, but these lesions were not clinically consistent with BP. ${ }^{17-19}$ In 1991, Grob et al. described what appears to be the first documented case of isolated extragenital HPV-16 ${ }^{+}$ BP confirmed by histological and molecular hybridization studies. ${ }^{20}$ The patient was a 44 -year-old north African man whose lesions occurred in an anatomical distribution virtually identical to that seen in our 

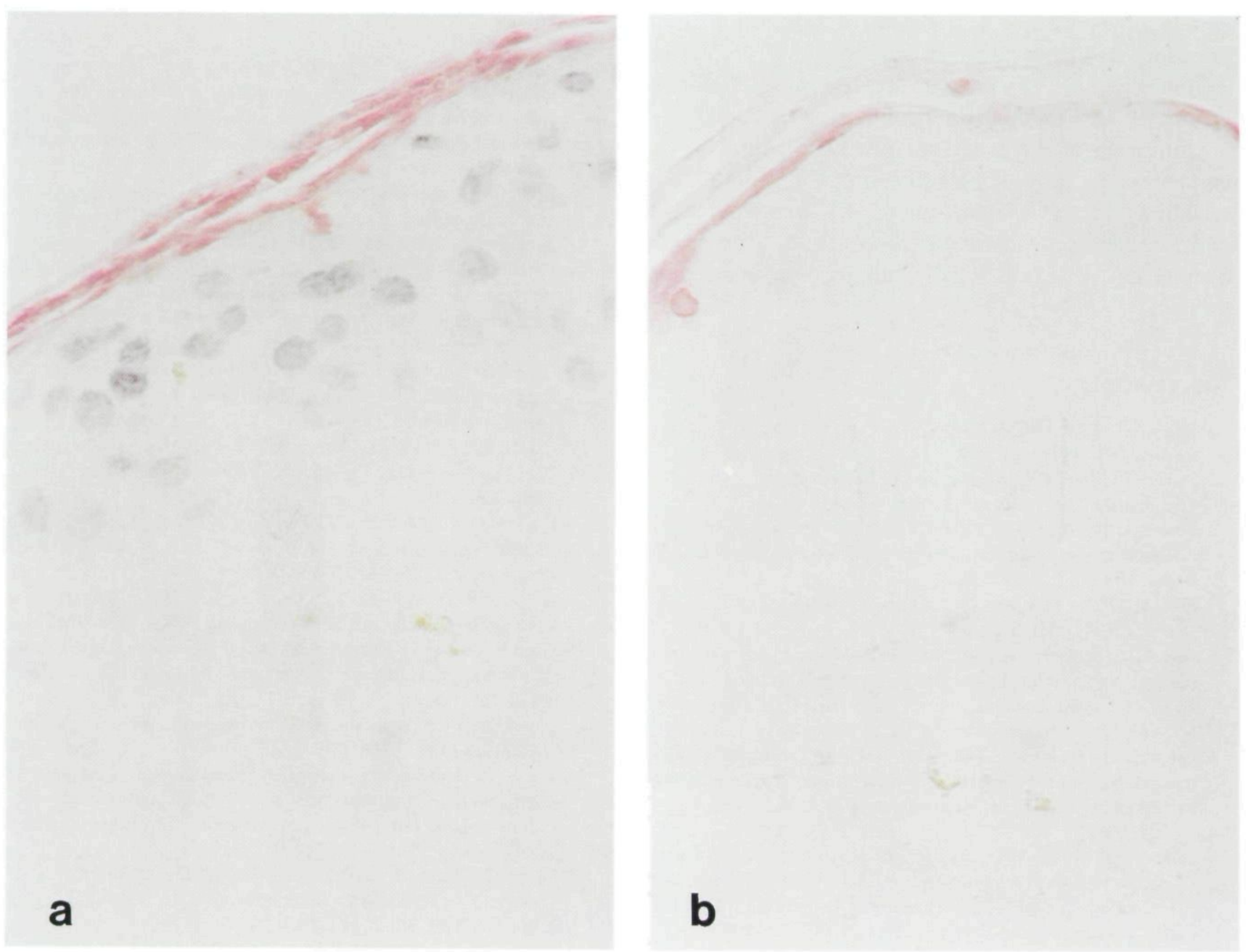

Figure 3. (a) In situ hybridization of the same specimen shown in Figure 2 for HPV DNA type within the thirties group (31/33/35). Heavy nuclear staining with naphthol blue demonstrates HPV DNA in the superficial epidermis. (b) Absence of staining for HPV DNA types 16 and 18 . Minimal melanin pigment is seen in the lower stratum spinosum.

patient. Unfortunately, HIV testing was not performed, and the patient was lost to follow-up.

Grob et al. suggested the possibility that their patient has used a contaminated razor, thereby accounting for the unusual distribution of his lesions. The razor might have been used previously by an HPV-infected sexual partner to remove pubic hair. ${ }^{20}$ There was no suggestion that this might have occurred in our patient, and he denied any recent sexual activity. He refused colposcopic examination of the anogenital region. Given his remote and nebulous history of genital 'warts', we cannot rule out subclinical infection of these sites which, by autoinoculation, may have led to anterior neck involvement.

Suggested therapy for BP includes superficial surgery with the $\mathrm{CO}_{2}$ laser, cryotherapy, electrodesiccation, and treatment with the neodymium: YAG laser. ${ }^{3,4,21}$
Topical retinoids, 5-fluorouracil, and interferon- $\alpha, \beta$, and $\delta$ can be effective. ${ }^{22,23}$ Despite initial therapeutic success, BP lesions, like condylomata, tend to recur. ${ }^{1,3,4}$

As far as we are aware, this is the first reported case of isolated extragenital HPV-thirties-group ${ }^{+} \mathrm{BP}$, and may be related to our patient's AIDS status. Isolated extragenital BP has been reported in a north African man of unknown HIV status who was HPV- $16^{+20}$ and, coincidentally, identical anatomical locations were involved in both patients. An $\mathrm{HIV}^{+}$patient with genital BP was found to be HPV- $33^{+}$, albeit weakly, by in situ hybridization, ${ }^{24}$ but given the strong HPV-16 positivity in that patient, however, it is not known whether the signal for HPV-33 resulted from cross-hybridization with HPV-16, in view of the known homology between them. Isolated extragenital BP may be an underreported phenomenon. Ideally, anogenital colposcopy 
should be performed to rule out subclinical genital infection. Evidence is accumulating that immunocompromised $\mathrm{HIV}^{+}$patients represent a high-risk group for HPV-related anogenital cancer. ${ }^{13,25,26}$ We are unaware of the progression of extragenital BP to carcinoma in any population or HPV subset. We recommend careful follow-up of $\mathrm{HIV}^{+}$patients with chronic verrucous extragenital $\mathrm{BP}$, and appropriate histological evaluation of changing or suspicious lesions.

\section{References}

1 Wade TR, Kopf AW, Ackerman AB. Bowenoid papulosis of the penis. Cancer 1978; 42: 1890-3.

2 Wade TR, Kopf AW, Ackerman AB. Bowenoid papulosis of the genitalia. Arch Dermatol 1979; 115: 306-8.

3 Patterson JW, Kao GF, Graham JH, Helwig EB. Bowenoid papulosis: a clinicopathologic study with ultrastructural observations. Cancer 1986; 57: 823-6.

4 Schwartz RA, Janniger CK. Bowenoid papulosis. J Am Acad Dermatol 1991; 24: 261-4.

5 Gross G, Hageborn M, Ikenberg $\mathrm{H}$ et al. Bowenoid papulosis: presence of human papillomavirus structural antigens and of HPV 16-related DNA sequences. Arch Dermatol 1985; 121: $858-63$.

6 Lookingbill DP, Kreider JW, Howett MK et al. Human papillomavirus type 16 in bowenoid papulosis, intraoral papillomas, and squamous cell carcinoma of the tongue. Arch Dermatol 1987; 123: 363-8.

7 Angerer IM, Stoler MH, Angerer RC. In situ hybridization with RNA probes-an annotated recipe. In: In Situ Hybridization: Applications to Neural Biology. (Valentino K, Eberwein J, Berkas J, eds). New York: Oxford University Press, 1987; 42-70.

8 Lever WF, Schaumburg-Lever G. Histopathology of the Skin, 7th edn. Philadelphia: J.B.Lippincott Company, 1990; 418.

9 Androphy EJ. Human papillomavirus. Current concepts. Arch Dermatol 1989; 125: 683-5.

10 Cobb MW. Human papillomavirus infection. J Am Acad Dermatol 1990; 22: 547-66.

11 Ikenberg H, Gissman L, Gross G et al. Human papillomavirus type 16-related DNA in genital Bowen's disease and in bowenoid papulosis. Int J Cancer 1983; 32: 563-5.

12 Favre M, Kremsdorf D, Jablonska S et al. Two new human papillomavirus types (HPV 54 and 55) characterized from genital tumours illustrate the plurality of genital HPVs. Int J Cancer 1990; 45: 40-6.

13 Rüdlinger R, Grob R, Yu YX, Schnyder UW. Human papillomavirus-35-positive bowenoid papulosis of the anogenital area and concurrent human papillomavirus-35-positive verruca with bowenoid dysplasia of the periungual area. Arch Dermatol 1989; 125: 655-9.

14 Rüdlinger R, Buchmann P. HPV 16-positive bowenoid papulosis and squamous cell carcinoma of the anus in an HIV-positive man. Dis Colon Rectum 1989; 32: 1042-5.

15 Kato T, Saijyo S, Hatchome N et al. Detection of human papillomavirus type 16 in bowenoid papulosis and invasive carcinoma occurring in the same patient with a history of cervical carcinoma. Arch Dermatol 1988; 124: 851-2.

16 Obalek S, Jablonska S, Beaudenon S et al. Bowenoid papulosis of the male and female genitalia: risk of cervical neoplasia. J Am Acad Dermatol 1986; 14: 433-44.

17 Ostrow RS, Shaver MK, Turnquist S et al. Human papillomavirus16 DNA in a cutaneous invasive cancer. Arch Dermatol 1989; 125: $666-9$.

18 Streamlau A, Gissmann L, Ikenberg $\mathrm{H}$ et al. Human papillomavirus type 16 related DNA in an anaplastic carcinoma of the lung. Cancer 1985; 55: 1737-40.

19 Abramson AL, Brandsma J, Steinberg B, Winkler B. Verrucous carcinoma of the larynx. Arch Otolaryngol 1985; 111: 709-15.

20 Grob JJ, Zarour H, Jacquemier J et al. Extra-anogenital HPV 16related bowenoid papulosis. Genitourin Med 1991; 67: 18-20.

21 Knoll LD, Segura JW, Benson RC Jr, Goellner JR. Bowenoid papulosis of the penis: successful management with neodymium: YAG laser. J Urol 1988; 139: 1307-9.

22 Gross G, Roussaki A, Schöpf et al. Successful treatment of condylomata acuminata and bowenoid papulosis with subcutaneous injections of low-dose recombinant interferon-alpha. Arch Dermatol 1986; 122: 749-50.

23 Gross G, Roussaki A, Papendick U. Efficacy of interferons on bowenoid papulosis and other precancerous lesions. J Invest Dermatol 1990; 95(Suppl.): 152-7S.

24 Rolighed J, Sørensen IM, Jacobsen NO, Lindeberg H. The presence of HPV types $6 / 11,13,16$ and 33 in bowenoid papulosis in an HIV-positive male, demonstrated by DNA in situ hybridization. APMIS 1991; 99: 583-5.

25 Milburn PB, Brandsma JL, Goldsman CI et al. Disseminated warts and evolving squamous cell carcinoma in a patient with acquired immunodeficiency syndrome. J Am Acad Dermatol 1988; 19: 401-5.

26 Kiviat NM, Critchlow CW, Holmes KK et al. Association of anal dysplasia and human papillomavirus with immunosuppression and HIV infection among homosexual men. AIDS 1993; 7: 43-9. 
This document is a scanned copy of a printed document. No warranty is given about the accuracy of the copy. Users should refer to the original published version of the material. 